\title{
It is ethical to diagnose a public figure one has not personally examined - CORRIGENDUM
}

\author{
J. Gartner, A. Langford and A. O'Brien
}

https://doi.org/10.1192/bjp.2018.132, Published by Cambridge University Press, 21 September 2018.

Keywords: Diagnosis; history of psychiatry; media; corrigendum.

In the introduction to this article, John Gartner was incorrectly referred to as a psychiatrist. He is in fact a psychologist.
J. Gartner, A. Langford, A. O'Brien

\section{Reference}

Gartner J, Langford A, O'Brien A. It is ethical to diagnose a public figure one has not personally examined. The British Journal of Psychiatry 2018; 213(5): 633-7. 